\title{
تخطيط تعليم اللغة العربية في معهد الجامعة والي سانجا سمارانج
}

\section{Nushah Ziadatul Ghoniyah ${ }^{{ }^{*}}$}

1UIN Maulana Malik Ibrahim Malang

\begin{abstract}
Today, the pesantren tradition has been transformed with many variations. One of the variants is the phenomenon of pesantren in the university/campus or known as the student ma'had. One of pesantren in university is ma'had Al-Jami'ah Walisongo which is located in the UIN Walisongo campus in Semarang. The existence of this ma'had is expected to develop the students' potential to have competence in the Arabic and English field. The things that will be discussed in this research are related to the planning of Arabic language learning. This type of research is qualitative research in the form of descriptive analysis with data sources in the form of documentation of the research results either scientific journals, etc. This study aims to find out about the learning planning from the aspects of how to formulate objectives, media, methods, teaching materials, and evaluation of Arabic learning. The results of this study are concluded in formulating learning objectives, it was adjusted to the vision and mission of ma'had Al-Jami'ah Walisongo. Teaching materials used are the book 'Silsilatun fî Ta'lîmi al-Lughati al'Arabiyyah - al-'Arabiyyah Basîthah', the learning media for the Ta'lim al-Lughah guidebook and its syllabies, generally the learning methods usedare drill and direct methods, and evaluation is conducted twice in odd and even semesters.
\end{abstract}

Keywords: Learning planning, Arabic learning, Ma'had Al-Jami'ah

*Korespondensi Penulis: nushahziadatul24@gmail.com 
Abstrak: Dewasa ini, tradisi pesantren telah bertransformasi dengan beragam variasinya. Salah satu variannya adanya fenomena pesantren masuk ke dalam kampus atau yang dikenal dengan ma'had mahasiswa. Dari beberapa perguruan tinggi yang didalamnya terdapat ma'had, salah satunya adalah ma'had Al-Jami'ah Walisongo yang terletak di lingkungan kampus UIN Walisongo Semarang. Adanya ma'had ini diharapkan dapat mengembangkan potensi mahasiswa agar memiliki kompetensi di bidang bahasa Arab dan Bahasa Inggris. Hal yang akan dibahas dalam penelitian ini berkaitan dengan perencanaan pembelajaran bahasa Arab. Jenis penelitian yang digunakan adalah penelitian kualitatif yang berbentuk analisis deskriptif dengan sumber data berupa dokumentasi dari hasil-hasil penelitian baik jurnal ilmiah, skripsi, atau thesis. Penelitian ini bertujuan untuk mengetahui tentang perencanaan pembelajaran dari aspek bagaimana merumuskan tujuan, media, metode, bahan ajar, dan evaluasi pembelajaran bahasa Arab. Hasil penelitian ini menghasilkan kesimpulan bahwa dalam merumuskan tujuan pembelajaran telah disesuaikan dengan visi, dan misi dari ma'had Al-Jami'ah Walisongo. Materi dan bahan ajar menggunakan buku 'Silsilatun fî Ta'lîmi alLughati al-'Arabiyyah - al-'Arabiyyah Basîthah', media pembelajannya buku panduan Ta'lim al-Lughah dan silabinya, metode pembelajaran pada umumnya menggunakan drill dan metode langsung, dan evaluasi dilakukan dua kali pada semester ganjil dan genap.

\section{Kata Kunci: Perencanaan pembelajaran, Pembelajaran bahasa} Arab, Ma'had Al-Jami'ah

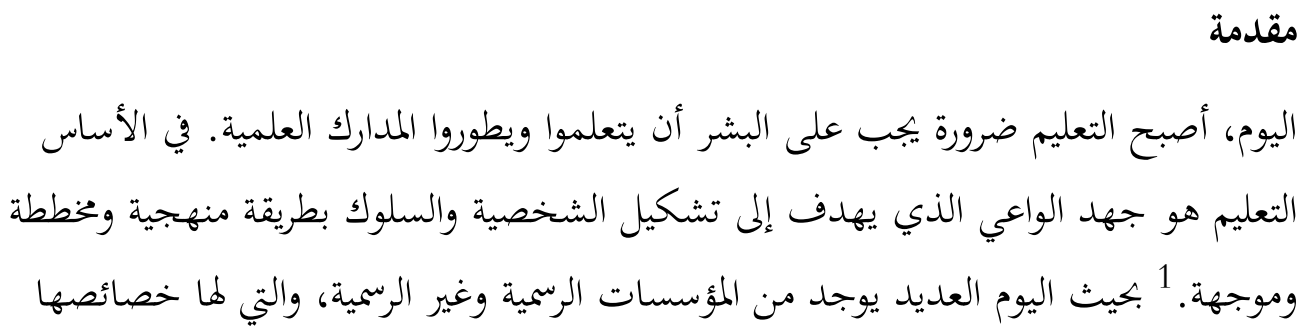

1 Bashori Muchsin, Moh Sulthon, dan Abdul Wahid, Pendidikan Islam humanistik: alternatif pendidikan pembebasan anak (Bandung: Refika Aditama, 2010), hlm. 3. 
ومزاياها. يعد وجود منظمات أو مؤسسات مختلفة في حياة الإنسان إحدى ظواهر الحياة الحديثة للمساعدة في تلبية احتياجات الحياة الفردية وفي المجتمع وتسهيلها. 2 في الوقت الحاضر، تم تحويل تقليد المعهد مع اختلافات مختلفة. أحد المتغيرات في هذا التعميم هو ظاهرة دخول المعهد إلى الحرم الجامعي أو ما يعرف بالمدرسة الطلابية. ينبع هذا من الوعي بأن نظام التعليم المعهد يعتبر فعال كمكان لغرس القيم الدينية. والأكثر من ذلك بالنسبة لطلاب التعليم العالي العام الذين سيصبحون فيما بعد علماء في تخصصات غير دينية، من المهم أن يكون 3 ثم يظهر النموذج التعليمي الذي يجمع بين تقاليد التعليم العالي وتقاليد المعهد ومن المتوقع أن ينتج خريجين يمكنهم فهم العلوم الحديثة أيضًا. أو بعبارة أخرى، من المتوقع أن يتمتع المتخرجون من الكليات الدينية الإسلامية (PTKI) بقدرات متساوية، وهي المنح الدراسية الدينية والمهنية. للإجابة على هذه المشكلة الكبيرة، فإن جامعة والي سانجا الإسلامية الحكومية سمارانج موجودة هنا للتغلب على هذه المشكلة، أي محاولة تطوير العلم من خلال التآزر بين تقاليد التعليم العالي وتقليد المعهد الذي هو تكامل في شكل معهد الجامعة والي سابجا. 4 من بين العديد من الجامعات التي يوجد بها معهد، إحداها معهد الجامعة والي سانجا الذي يقع داخل حرم الجامعة والي سانجا الإسلامية الحكومية في سمارانج. معهد الجامعة والي سابجا عنصر مكمل في بيئة جامعة والي سابجا الإسلامية الحكومية. لا يقدم هذا البرنامج درجة خاصة، ولكن هناك حاجة ملحة لتحسين جودة جامعة والي سانجا الإسلامية الحكومية سمارانج. يهدف هذا

2 Siti Raudhatul Jannah, "Karakteristik dan Spektrum Manajemen Pendidikan Islam," Al-Fikrah: Jurnal Kependidikan Islam IAIN Sulthan Thaha Saifuddin 4 (2013): hlm. 122.

${ }^{3}$ Khozin, Jejak-jejak Pendidikan Islam di Indonesia: Rekonstruksi Sejarah untuk Aksi [The footsteps of Islamic education in Indonesia: Reconstructing history for action](revised edition) (Malang: UMM Press Malang, 2006), hlm. 63.

4 Jamaluddin Shiddiq, "Model Pembelajaran Bahasa Arab di Ma'had Al-Jami'ah Walisongo Semarang," LISANIA: Journal of Arabic Education and Literature 2, no. 2 (2018): hlm. 103. 
البرنامج إلى خلق جو من التعليم وعملية تعليم تتيح للطلاب تطوير إمكاناتم بنشاط للحصول على كفاءات في مجالات اللغة العربية والإنجليزية كتوفير لقراءة الآداب الأجنبية اللازمة في أثناء المحاضرات في كلياقم.

بالإضافة إلى ذلك، مع الكفاءة في مجال اللغتين هما اللغة العربية و اللغة الإنجليزية، يمكنهم العمل في الكتابة، في شكل كتب ومجلات ومقالات متنوعة. يتيح إنشاء بيئة لغوية للطلاب استخدام

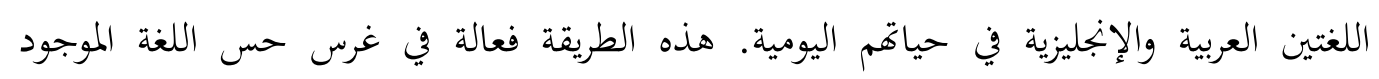
بداخلهم بحيث يكون من السهل إتقان اللغة التي يتم تعلمها بشكل نشط وسلبي.

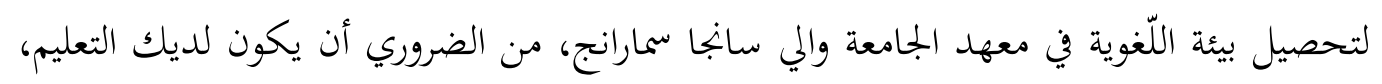
أحدها هو تعليم اللغة العربية. في هذه الحالة تحقيق التعليم مهم في التخطيط. يعد تخطيط التعليم

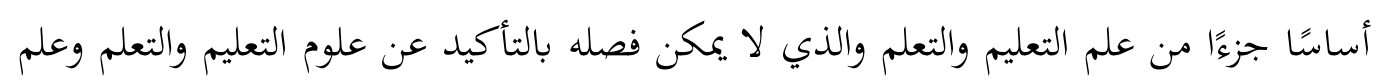
نفس التعليم وطرق التعليم وإدارة التعليم والتعلم وغيرها. 6 ستناقش هذه الدراسة كيفية التخطيط لتعليم اللغة العربية الذي يتضمن الأهداف والوسائل والطريقة والمواد والتقويم في عملية التعليميّة بعمهد الجامعة والي سانجا سمارانج.

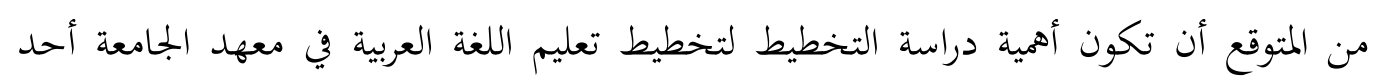

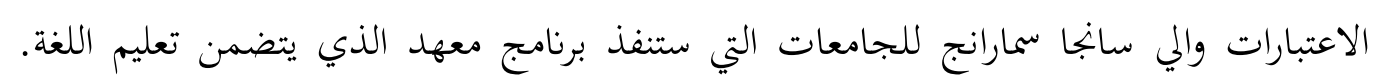

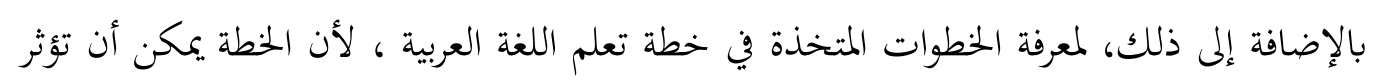

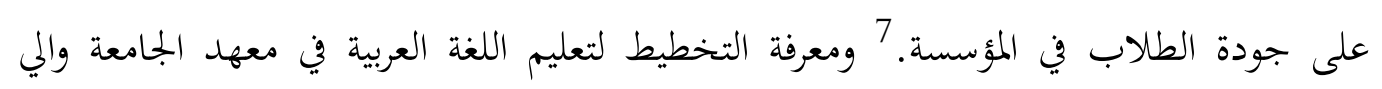

\footnotetext{
5 “Selayang Pandang |," diakses 31 Desember 2020, http://mahad.walisongo.ac.id/?page_id=16.

6 Munir, Perencanaan Sistem Pengajaran Bahasa Arab; Teori Dan Praktik (Jakarta: Kencana, 2016), hlm. 2.

7 Varda Himmatul Aliyah dan Danial Hilmi, "Manajemen Perencanaan Program Bahasa Arab Di Mayantara School Malang," Arabia 11, no. 1 (2019): hlm. 178.
} 
سانجا سمارانج من المتوقع أن يكون المقياس الأولي للجامعات التي ترغب في جعل تعليم اللغة في الجامعات التي توجد بها معهد. في سياق التدريس، يمكن تفسير التخطيط على أنه سلسلة من العمليات لتجميع المواد التعليمية والوسائط والأساليب والنهج والتقييمات لفترة زمنية معينة لتحقيق الهدف. 8 سيكون نشاط التعليم أكثر مثالية عندما يكون المعلم أكثر قم أولاً بإعداد خطة الدرس. بالإضافة إلى ذلك، من المتوقع أيضًا أن يكون المعلم أكثر إبداعًا. ومبتكرة في تقديم خطط التعليم التي تم تحويلها إلى أنشطة تعليمية فعلية.9 من بين العديد من المدارس الداخلية الإسلامية في الحرم الجامعي، يرتبط معهد الجامعة والي سانجا سمارانج الذي سيتم دراسته بكيفية تخطيط تعليم اللغة، وخاصة اللغة العربية. من المتوقع أن يتم استخدام إلحاح دراسة تخطيط تعلم اللغة العربية في معهد الجامعة والي سانجا كاعتبار للحرم الجامعي أو الجامعات التي ستنشئ معهدًا في الحرم الجامعي. يؤثر تخطيط التعلم أيضًا على جودة الطلاب في المؤسسة. بالإضافة إلى ذلك، من المتوقع أن تكون معرفة التخطيط التعليمي في معهد الجامعة والي سانجا مقياسًا أو معيارًا أوليًا لأولئك الذين يرغبون في إنشاء مدرسة داخلية إسلامية في الحرم الجامعي. إن البحث الذي درس تعليم اللغة في المعهد هو بحث أجرته إيفا أردينال بعنوان "إدارة تعليم اللغة في تحسين مهارات اللغة العربية والإنجليزية (دراسات في معهد الجامعة كيرينجي)". 10 تظهر نتائج هذه الدراسة أن تنفيذ التعليم في معهد الجامعة الكرينجي يتم في الفصل، ولكل الفصل مدرس، والطريقة المستخدمة في الكلام في كل درس هي بشكل عام طريقة Drill والطريقة المباشرة. في

8 Abdul Majid, "Perencanaan pembelajaran mengembangkan kompetensi guru," Bandung: PT Remaja Rosdakarya, 2011, hlm. 17.

9 M. Nadlir, "Perencanaan pembelajaran berbasis karakter," Jurnal Pendidikan Agama Islam (Journal of Islamic Education Studies) 1, no. 2 (2013): hlm. 339.

10 Eva Ardinal, "Manajemen Pembelajaran Bahasa Dalam Meningkatkan Kemampuan Bahasa Arab Dan Inggris (Studi Di Ma'had Al-Jami'ah IAIN Kerinci)," Tarbawi: Jurnal Ilmu Pendidikan 13, no. 1 (2017): hlm. 83.

241 | Tarbiyatuna: Jurnal Pendidikan Ilmiah Vol. 5 No. 2 (Desember) 2020 
Nushah Ziadatul Ghoniyah

تحسين المهارات اللغوية، يضطلع المدرسون بمهمة التوجيه والتدريس ونقل المعرفة للطلاب بالإضافة إلى العديد من المهارات مثل التحدث باللغة الأجنبية ورواية القصص ومناقشة اللغات الأجنبية وغيرها.

موقع الاختلاف بين البحث ومناقشة المؤلف هو حول أهداف البحث والمؤسسة قيد الدراسة. الغرض من هذا البحث هو أن هذه الدراسة تمدف إلى تحديد إدارة تعلمي اللغة في تحسين مهارات اللغة العربية والإنجليزية. في حين أن هدف المؤلف في هذه الدراسة هو معرفة كيف أن التخطيط التعليمي في معهد الجامعة والي سانجا سمارانج مبني على النظرية التي طرحها (عبد المجيد: 2011) في كتابه الذي ينص على أن تخطيط التعليم يتم من خلال اتخاذ قرارات منها: 1) وأهداف التعليم 2) المادة التي سيتم تدريسها، 3) والطريقة أوالأساليب أوالاستراتيجيات لتحقيق الأهداف، 4) وتقويم تحصيل الطلاب وتقدم التعليم. لذلك، في هذه الدراسة فإها تركز على المكونات أو المحتوى في تخطيط التعليم، بما ذلك والأهداف والمواد والوسائل والطريقة والتقويم في التعليم اللغة العربية بجامعة والي سانجا الإسلامية الحكومية سمارانح.

\section{منهج البحث}

هذا النوع المستخدم في هذا البحث هو بحث نوعي. صرح بوكدان وتيلور أن النهج النوعي هو البحث الذي يمكن أن يجصل على بيانات مكتوبة وشفوية في عملية المراقبة المتعمقة لموضوع البحث. 11 هذا البحث هو منهج نوعي ذو طبيعة وصفية ويميل إلى استخدام مفهوم التحليل. هدف هذه الدراسة إلى تحديد التخطيط لتعليم اللّغة العربية في ما كان معهد الجامعة والي سانجا سمارانج من جوانب كيفية صياغة الأهداف والوسائل والطريقة أوالأساليب والمواد التعليمية والتقييم

${ }^{11}$ Lexy J. Moleong, Metodologi penelitian kualitatif (Bandung: Remaja Rosda Karya, 2014), hlm. 3.

Tarbiyatuna: Jurnal Pendidikan Ilmiah Vol. 5 No. 2 (Desember) 2020 | 242 
قي تعليم اللغة العربية. بينما الأداة المستخدمة في هذا البحث هي التوثيق. مصدر بيانات التوثيق في هذا البحث هو في شكل وثائق متعلقة بالمؤسسات تم الحصول عليها من نتائج البحث في شكل بجلات علمية أو أطروحات.

\section{نتيجة البحث}

طبيعة تخطيط التعليم

التخطيط لغةً التصميم. وفي الوقت نفسه، من حيث تصميم شيء ما بطريقة معينة وفقا للمبادئ

والمبادئ ويمكن تحقيق الأهداف. تخطيط التعلم هو عملية تصميم تعلم تتضمن عملية التعليم. 12 وفقًا لصابرين، فإن التخطيط هو إعداد خطوات النشاط التي سيتم تنفيذها لتحقيق أهداف محددة مسبقًا، والتي يتم ترتيبها بناءً على فترة زمنية معينة، وهي طويلة ومتوسطة وقصيرة المدى. في صنع التخطيط، فإن أهم مبدأ هو أنه يجب تنفيذه بسهولة وعلى الهدف. 13 أمّا عند ماجد إن التخطيط هو خطوة يتم إعدادها لتحقيق هدف محدد سلفًا خلال فترة زمنية معينة وفقًا لرغبات المخطط. وفقًا عند Reigeluth، فإن التخطيط للتعلم هو علم يهتم بفهم طرق التعلم وتحسينها وتطبيقها بهدف تحديد طريقة التعلم الأنسب للطلاب. يعد خخطط التعلم أداة مفيدة للغاية ، حيث تعمل على الجمع بين الموارد والتوثيق التاريخي بكيث يعكس فلسفة التدريس، وعدد الطلاب، والكتاب المدرسي، والأهم من ذلك، هدفه المتمثل في تحسين تعلم الطلاب في الفصل الدراسي.

12 Muhammad Ali Al-Khauly, Qamus al-Tarbiyah Inggris Arab (Beirut: Dar-li ilmi alMalayin, 1981), hlm. 335.

${ }^{13}$ Sabirin, "Perencanaan Kepala Sekolah Tentang Pembelajaran," Jurnal Tabularasa PPS Unimer 9, no. 1 (Juni 2012): hlm. 113.

${ }^{14}$ Majid, "Perencanaan pembelajaran mengembangkan kompetensi guru," hlm. 15.

243 | Tarbiyatuna: Jurnal Pendidikan Ilmiah Vol. 5 No. 2 (Desember) 2020 
فلذلك من المفهوم عن التخطيط المذكورة، يعد تخطيط التعليم خطوات عملية لتحقيق أهداف معينة في المستقبل. التخطيط هو عملية مهمة في التعليم، والتي يتم تنفيذها من المعلمين قبل تعليم طلابكم في الفصل. بناءً على هذه الاستنتاجات، يمكن القول أن تخطيط تعلم اللغة العربية هو عملية صنع قرار نابحة عن التفكير العقلاني في أهداف وغايات تعليم اللغة العببة كمحاولة لتحقيق الأهداف. من خلال الاستفادة من جميع الإمكانات والموارد التعليمية. كعملية تعاونية، يعمل المعلمون والطلاب معًا لتحقيق أهداف التعليم المحدة مسبقًا. وبالتالي، فإن إدراك المعلمين والطلاب وفهمهم للأهداف المراد تحقيقها هو شرط مطلق وغير قابل للتفاوض. وفقًا لما ذكره ماجد (2006)، يمكن رؤية مفهوم تخطيط التعليم من وجهات نظر مختلفة، مثل التكنولوجيا، كنظام، كعلم ، كعملية وكواقع. 15 - تخطيط التعليم كتكنولوجيا، في تخطيط التعليم يتم باستخدام تقنيات واستخدام التكنولوجيا التي يمكن أن تطور السلوك المعرين والنظريات البناءة التي يمكن أن توفر حلولاً لمشاكل التعليم التي تنشأ في عالم التعليم. - تخطيط التعليم كنظام، في بتميع استراتيجيات تخطيط التعليم، والنماذج، والنهج، والطرق، والوسائط، والأدوات، والموارد، والإجراءات التي يمكن استخدامها لدفع التعليم. - تخطيط التعليم كجهاز، هو فرع من فروع المعرفة الذي يهتم دائمًا بنتائج البحث في مجال التعليم والتعلم وتطوير النظريات واستراتيجيات التدريس المطورة والمنفذة في تخطيط وتنفيذ التعلم.

15 Sabirin, “Perencanaan Kepala Sekolah Tentang Pembelajaran,” hlm. 118. 
- تخطيط التعليم كالعلم، هو نشاط لإنشاء المواصفات التفصيلية لتطوير وتنفيذ وتقويم وصيانة المواقف والمرافق التعليمية للوحدات التي تكون واسعة أو أضيق من معيار الكفاءات الأساسية والموضوع درس محدد سلفا بكل تعقيداته. - - تخطيط التعليم كعملية هو طريقة منهجية لتطوير التعلم القائم على نظريات التعليم والتدريس بدءًا من تحليل احتياجات عملية التعليم وأنشطة التدريس والتعليم إلى تقويم الموضوع وأنشطة التعليم التي يقوم بها المعلم. - - تعليم التخطيط كحقيقة أن تطوير تخطيط التعليم من خلال النظر إلى واقع أنشطة التعليم من وقت لآخر في عملية يتم تنفيذها بطريقة مخططة ودقيقة ومنهجية بناءً على متطلبات تطوير العلم والتكنولوجيا.

لذلك، فإن إعداد تخطيط التعليم يجب أن ينتبه إلى تخصصات العلوم والأنظمة والتكنولوجيا بكيث يمكن تنفيذ أهداف أنشطة التعليم بفعالية وكفاءة. بالإضافة إلى ذلك، يجب أن ينتبه التعليم أيضًا إلى الأهداف والكفاءات التي يجب تحقيقها والتي يتم تعديلها وفقًا لرؤية ورسالة المؤسسة.

\section{صياغة أهداف تعليم اللغة العربية}

التخطيط هو أحد المكونات الموجودة في الإدارة. والمعني التخطيط في هذه الحالة هو التخطيط لتعليم اللغة العربية. التخطيط هو بحميع الخطوات التي سيتم تنفيذها لتحقيق الأهداف المحددة مسبقًا. من هذا التعريف، يتم التخطيط لتحقيق هدف محدد مسبقًا. الخطوة الأولى التي يجب اتخاذها في تخطيط التعليم هي صياغة الهدف. يتم التخطيط للتعليم من خلال اتخاذ قرارات منها: 1) أهداف التعليم لوحدة التعليم التي يجب تحقيقها و 2) المواد التي سيتم تدريسها، 3) الوسائل 
Nushah Ziadatul Ghoniyah

والطريقة التعليمية لتحقيق هذه الأهداف 4) تقويم تحصيل الطلاب وتقدم التعليم. 16 لذلك، فإن صياغة هدف التعليم مهمة جدًا في التخطيط. في تعليم اللغة، يمكن أن يكون هذا الهدف في شكل نوع واحد أو عدة أنواع من المهارات اللغوية، وإتقاهما أمر ضروري، لذلك يجب رعايتها وتحسينها. يعتبر التحديد الصحيح والتفاصيل الكاملة لأنواع المهارات اللغوية المستخدمة لغرض التدريس جزءًا مهمًا وحاسمًا في تخطيط التعليم، وبالتالي يجب صياغته بعناية. سيؤدي تحديد وتفاصيل أهداف التعليم إلى تلوين وتأثير وحتى تحديد أسلوب وابتاه الأنشطة التعليمية، والتي تمدف إلى تحقيق أهداف تنفيذها. 17 أمّا بالنسبة لصياغ أهداف التعليم، فمن الضروري معرفة رؤية ورسالة معهد الجامعة والي سابجا أولاً، كما وثقها 1. الباحث من التحصيل المباحث، فإن رؤية ورسالة معهد الجامعة والي سانجا هي كما يلي:

رؤية المؤسسة أساسية للغاية. الرؤية هي فكرة أو أفكار يتم التعبير عنها بناءً على ظروف المؤسسة التي تدار لتحقيق الأهداف المرجوة. 18 الرؤية الصحيحة ستعني فائدة المؤسسة. كما يرى كومريا وترياتنا أنه برؤية، سوف يرتفع الحماس مرة أخرى، ويكسن الأداء ويعززه، ويكقق الإنجازات التعليمية ، ويخلق التفكير المستقل. 19

${ }^{16}$ Nur Indah Tri Susdiasih, "Manajemen pembelajaran bahasa dalam meningkatkan kemampuan berbahasa asing (studi di Ma'had Al-Jami'ah Walisongo Semarang)" (UIN Walisongo, 2015), hlm. 50.

17 Shodiq Abdullah, Evaluasi Pembelajaran konsep dasar, teori dan aplikasi (Semarang: Pustaka Rizki Putra, 2012), hlm. 4.

18 Ika Alifiyah, Ali Imron, dan Juharyanto Juharyanto, "Kepemimpinan Visioner Kepala Sekolah dalam Mengembangkan Karakter Peserta Didik," JAMP: Jurnal Administrasi dan Manajemen Pendidikan 2, no. 1 (2019): hlm. 36.

19 Aan Komariah dan Cepi Triatna, Visionary leadership menuju sekolah efektif (Jakarta: Bumi Aksara, 2005), hlm. 81. 
تتمثل رؤية معهد الجامعة والي سانجا في دعم تحقيق علماء الجامعة والي سانجا الاسلامية الحكومية سمارانج الذين لديهم شخصيات إسلامية وقادرون على التحدث باللغتين هما العربية والإنجليزية. 20 إن رؤية معهد الجامعة والي سانجا دقيقة للغاية، تبدأ من أخذ كلمات مباشرة وقصيرة وسهلة الفهم وموجهة نحو المستقبل. كما ذكر إدوين أ. لوك، 21 الذي ينص على أن السمة المميزة في تكوين الرؤية هي استخدام جمل قصيرة وبسيطة وواضحة وسهلة الفهم، يحبها عامة الناس، والتوجيه هو المستقبل. لذلك، يجب أن ينتبه وضع الرؤية إلى قدرتين: 1) القدرة على ملاحظة التغيير في المستقبل من جلسة الابحاه. 2) القدرة على وصف التغييرات التي سيتم إجراؤها في ذلك الوقت.

$$
\text { 2. بعثة معهد الجامعة والي سانجا }
$$

بعد تشكيل الرؤية، سيتم تطوير الرؤية إلى عدة مهام. المهمة هي خيار أو مسار تختاره مؤسسة تعليمية أو منظمة لطلابها أو بجتمعها. 22 إن صياغة المهمة تعني عمل خريطة للرحلة التي يتعين القيام بها. من خلال عمل خريطة تصور بلدقة العالم الذي سيتم إدخاله، سيتم إنشاء فرصة للمؤسسة أو المنظمة لإدارة وتلبية احتياجات بيئتها بحيث يتم ضمان تطورها وبقائها. 23 من الرؤية التي تم ذكرها، يجب أن تكون هناك مهمة من معهد الجامعة والي سونجا سمارانج، 24. أ) للتنمية جو أكاديمي ملائم

20 Susdiasih, "Manajemen pembelajaran bahasa dalam meningkatkan kemampuan berbahasa asing (studi di Ma'had Al-Jami'ah Walisongo Semarang)," hlm. 90.

${ }^{21}$ Ismail, "Visi dan Misi Depag" (Balai Diklat Pegawai Teknis Keagamaan Surabaya, 2005), hlm. 16.

${ }^{22}$ M. A. Mulyono, Manajemen Administrasi dan Organisasi Pendidikan (Yogyakarta: Ar-Ruzz Media, 2008), hlm. 120.

23 Aliyah dan Hilmi, "Manajemen Perencanaan Program Bahasa Arab Di Mayantara School Malang," hlm. 17.

24 Susdiasih, "Manajemen pembelajaran bahasa dalam meningkatkan kemampuan berbahasa asing (studi di Ma'had Al-Jami'ah Walisongo Semarang)," hlm. 90. 
Nushah Ziadatul Ghoniyah

$$
\text { ج) للتعزيز استيعاب القيم الإسلامية }
$$

إن وظيفة معهد والي سانجا هي وسيلة لرعاية الطلاب وتطوير المعرفة الدينية واللغوية بالإضافة إلى تعزيز والحفاظ على تقاليد الروحانية الدينية لدعم تحقيق رؤية ورسالة وأهداف جامعة والي سانجا الاسلامسة الحكومية.

بعد الرؤية والرسالة التالية، وهي الأهداف، فإن أهداف معهد الجامعة والي سانجا هي كما يلي: أ) لديهم قدرات أكاديمية تنافسية ب) القدرة على التحدث باللغة العربية ج) القدرة على التحدث والكتابة باللغة الإنجليزية د) قادرة على قراءة الكتب الكلاسيكية والمعاصرة

بعد رؤية ورسالة وأهداف معهد الجامعة والي سانجا، هناك أهداف خاصة في تعليم اللغة العربية ، وهي: أ) قادر على إتقان المفردات للمحادثات اليومية في الحرم الجامعي. ب) ماهر في اللغتين العربية والإنجليزية في الحياة اليومية في الحرم الجامعي. ج) معتاد وثقة في استخدام اللغتين العربية والإنجليزية في التواصل اليومي. د) ماهر في إلقاء المحاضرات أو إلقاء الخطب باللغتين العربية والإنجليزية. هـ) لديه أساسيات تطوير إتقان الكتاب الأصفر. 25 لذلك، من بعض أهداف تعليم اللغة المذكورة في معهد الجامعة والي سانجا سمارانج، من المعروف أن الأهداف لا تغطي فقط الجانب المعريف ولكن أيضًا الجوانب النفسية الحركية. بينما في صياغة أهداف التعليم، تم تعديلها سابقًا مع رؤية ورسالة ووظيفة معهد الجامعة والي سانجا سمارانج.

25 Susdiasih, hlm. 90.

Tarbiyatuna: Jurnal Pendidikan Ilmiah Vol. 5 No. 2 (Desember) 2020 | 248 
بعد صياغة أهدف تعليم اللغة العربية، والذي يتم تعديله وفقًا لرؤية ورسالة ووظيفة معهد الجامعة والي سانجا، ثم تحديد المواد التعليمية كمبادئ توجيهية في عملية تعليم اللغة العربية لاحقًا والتي تم تعديلها وفقًا للأهداف التي تم تحديدها.

تعتبر المواد التعليمية عاملاً مهمًا في فعّالية التعليم. يمكن أن يؤثر نقص المواد التعليمية بالتأكيد على جودة التعلم. مواد تعليم اللغة العربية مواد تعليم اللغة العربية وهي مزيج من المعرفة والمهارات وعوامل الموقف، مرتبة بشكل منهجي بحيث يمكن للمدرسين والطلاب استخدامها في عملية تعليم اللغة العربية. 26 المادة التعليمية لتعليم اللغة المستخدمة في معهد الجامعة هي كتاب بموضوع "سلسلة في تعليم اللغة العربية - العربية بسيطة". هذا الكتاب هو تبني وتكييف لكتاب "سلسلة علمي اللغتي العربية - المستوَى الثاني" الصادر عن جامعة الإمام محمد سعود الإسلامية بالمملكة العربية السعودية ولكن مع بعض التغييرات المصممة لاحتياجات الأطفال. 27

تحتوي مادة هذا الكتاب على عدة جوانب، منها: المفردات والقرعة والتدريب والقواعد. بشكل عام، يمكن وصف بنية هذا الكتاب على النحو التالي: 1) عرض المفردات المتعلقة بالمواضيع، 2) عرض القراءة، 3) قائمة الأسئلة المتعلقة بالقراءة، 4) مناقشة القواعد، 5) التدريبات المتعلقة بالمواد النحوية. 28 لذا فإن المادة المستخدمة في تعليم اللغة العربية في معهد الجامعة تم تعديلها لتناسب الكتاب الذي تم تجميعه.

${ }^{26}$ M. Abdul Hamid, Danial Hilmi, dan M. Syaiful Mustofa, "Pengembangan Bahan Ajar Bahasa Arab Berbasis Teori Belajar Konstruktivisme untuk Mahasiswa," Arabi: Journal of Arabic Studies 4, no. 1 (2019): hlm. 105.

27 Shiddiq, “Model Pembelajaran Bahasa Arab di Ma'had Al-Jami'ah Walisongo Semarang," hlm. 107.

${ }^{28}$ Shiddiq, hlm. 107.

249 | Tarbiyatuna: Jurnal Pendidikan Ilmiah Vol. 5 No. 2 (Desember) 2020 
لذلك، في تخطيط التعليم، بالإضافة إلى الأهداف من المهم أيضًا تحديد المواد التعليمية المستخدمة في عملية التعليم. حيث يتم تعديل المواد التعليمية وفقًا للأهداف وكفاءات التعليم التي تم تحديدها بحيث يمكن هيئة هذه الأهداف بشكل صحيح كما هو متوقع. لذلك، من حيث المواد التعليمية، يستخدم معهد الجامعة والي سانجا كتاب سلسلة في تعليم اللغة العربية.

\section{تحديد وسائل وطرق التعليم}

بعد صياغة الهدف وتحديد المواد التعليمية في تحطيط تعليم اللغة العربية، ثم تحديد الوسائل والطريقة المستخدمة لعملية التعليم. الوسائل هي وسيلة مساعدة بصرية تستخدم كوصف للمواد التي ينقلها المعلمون إلى الطلاب في عملية تعلم اللغة الأجنبية. الأشياء التي يجب تحضيرها في وسائط التعلم بمعهد الجامعة والي سانجا هي كالنالي: دليل تعليم اللغة ومناهجها التي تحتوي على تعبيرات ومفردات التي غالبا ما تستخدم في التواصل ثنائي اللغة، وهما العربية والإنجليزية.

التخطيط لتعليم اللغات الأجنبية يستخدم المنهج وخطة تنفيذ التعليم التي أعدها مصريفة ورئيس المركز لتحقيق الهدف المخطط. هناك العديد من الكفاءات اللغوية التي يجب أن يجققها التربويون

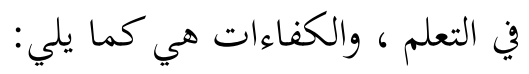
أ. أ. خلق بيئة لغوية

ب. مساعدة الطلاب الذين يعانون من مشاكل في فهم المواد اللغوية في الكلية، الإيجابي والسبي. ج. أسبوع اللغة العربية وأسبوع اللغة الإنجليزية د. المسابقة للعببية والإنجليزية والتي أقيمت لتحفيز طاقات الطلاب من خلال مسابقات الإنجاز وقياس إتقان اللغة الأجنبية وكفاءة كل طالب. 
هـ. محادثة التي تقام كل صباح قبل الأنشطة في الحرم الجامعي والتي تحتوي على المفردات اللغة العربية أو النجليزية إضافية وتدرب الطلاب على التحدث باللغات الأجنبية بانتظام.

تعليم اللغة العربية في معهد الجامعة والي سانجا يعرف عادة بفصل اللغة. هذا البرنامج هو نظام لتعليم اللغة العربية يجب أن يتبعه كل الطالبات لمدة فصلين دراسيين أوسنة واحدة. بالنسبة للسنوات الثانية والسنوات اللاحقة، فإن فصل اللغة هذا ليس إلزاميًا أو موصى به للطالب فقط، لأن الطالبات اللتين دخلوا عامهم الثاني أصبحوا من كبار السن وحتى مدربين للطلاب الآخرين. تستخدم عملية التعليم في هذا البرنامج نموذجًا كلاسيكيًا يدرسه محاضر . يتكون برنامج تعليم اللغة هذا من 11 فصلاً، والتي تنقسم إلى 3 مستويات، وهي: 1) فصل الابتداء، ويتكون من 8 فصول، 2) فصل المتوسط، ويتكون من فصلين ، 3) فصل العليى ويتكون من فئة واحدة. يتكون كل فصل من 30 طالبًا. 29 وظيفة وغرض هذه البيئة اللغوية هي كبرنامج دعم لفعالية البرنامج الرئيسي، أي برنامج المحدثة اليومية (التحدث باللغة العربية بشكل نشط ليوم كامل في بيئة المعهد). والثاني يؤكد على تحقيق جانب الكفاءة في الاتصال، والأول يؤكد على الاستخدام الصحيح للجمل حسب الجانب النحوي.

طريقة التعليم المستخدمة في فصل اللغة هذا هي طريقة التعليم على النحو التالي: 1) يفتح المعلم الفصل بإدراك يتضمن التحية والتحفيز وشرح أهداف التعليم باللغة العربية. 2) يقدم المعلم مادة مفردة واحدة، أو يقلد الطلاب، أو يستمعون فقط، 3) يقدم المعلم مادة عن القواعد، ويستمع الطلاب بعناية. 4) يقترح المعلم أمثلة لتطبيق القواعد، 5) طُلب من الطالبات تقديم مثال بلغتها. 6) يعطي المعلم مكافآت للإجابات الصحيحة ويعاقب الإجابات الخاطئة. 7) يراجع المعلم

${ }^{29}$ Shiddiq, hlm. 107.

251 | Tarbiyatuna: Jurnal Pendidikan Ilmiah Vol. 5 No. 2 (Desember) 2020 
باختصار المادة المذكورة أعلاه، 8) يختم المعلم ويؤكد، 9) يغلق المدرس الفصل بتقديم ملخص موجز، والاختتام، والتحفيز باللغة العربية، والتحية. من خطوات تعليم اللغة العربية ما هو إلا وصف عام. يختلف تطبيق أساليب وإجراءات التعليم لكل معلم، لأن المعلم نفسه يعرف نقاط القوة والضعف لدى الطلاب، ولكن ما يستخدم غالبًا في التعليم هو الطريقة Drill والطريقة المباشرة. 30 من شرح نتائج التوثيق المذكور، يمكن استنتاج أنه بعد صياغة الهدف والمواد التعليمية وتحديدها، فإن الخطوة التالية في تخطيط التعليم هي تحديد الوسائل وطريقة التعليم المستخدمة. حيث الوسائل المستخدمة هي "دليل التعليم اللغة"، والطرق المستخدمة في تعليم اللغة العربية في معهد الجامعة تستخدم بشكل عام الطريقة والطريقة Drill المباشرة. ومع ذلك، لا يزال بإمكان المعلم أو المعلم اختيار الطريقة الصحيحة وفقًا لقدرات الطلاب.

\section{تحديد التقويم}

بعد صياغة الأهداف والمواد التعليمية والوسائل والطريقة المستخدمة، فإن آخر شيء في عملية التخطيط التعليمية هي كيفية تقويم التعليم الذي سيتم تنفيذه لتحديد تقدم الطلاب أثناء عملية التعليم التي كانت مستمرة وتم تنفيذها.

قال إدوين و رامايوليس إن التقويم ينطوي على إجراء أو عملية في تحديد قيمة شيء ما (رامل يولوس، 2002) كان الغرض من التقويم الذي تم إجراؤه في معهد الجامعة والي سانجا سمارانج هو تحديد مدى قدرة الطلاب على فهم ما يدرسه المعلمون. تقويم تعليم اللغة الأجنبية في جميع الفصول هو نفسه. يستخدم هذا التقويم في الأساس اختبارًا كتابيًا واختبارًا شفهيًا. تقويم التعليم

30 Susdiasih, "Manajemen pembelajaran bahasa dalam meningkatkan kemampuan berbahasa asing (studi di Ma'had Al-Jami'ah Walisongo Semarang)," hlm. 100.

Tarbiyatuna: Jurnal Pendidikan Ilmiah Vol. 5 No. 2 (Desember) 2020 | 252 
الذي يتم إجراؤه للطلاب، بالطبع هناك تعديلات تم إجراؤها، مثل تعديلات الوقت والنهج الفردية.

فإن تقويم التعليم وفقًا لوحيو ستيابودي هو عملية جمع ومعالجة البيانات حول نظام التعليم، وخاصة نتائج تعلم الطلاب من أجل الحصول على صورة واضحة لمدى تحقيق أهداف التعلم لتحسين وتحسين جودة التعلم. 31 لذلك، فإن تقويم التعليم هو نشاط لتقويم أو تصحيح الأشياء التي حدثت أو تم القيام بها أثناء أنشطة التعليم التي حدثت. أو بعبارة أخرى، هو نشاط يكررونه لاكتشاف أشياء مهمة في شكل مزايا وعيوب تحدث في أنشطة التعليم التي جرت على أمل أن يتمكنوا من بذل قصارى جهدهم أثناء أنشطة التعلم التي سيتم تنفيذها لاحقًا. كان الغرض من التقويم الذي تم إجراؤه في معهد الجامعة والي سانجا سمارانج هو معرفة مدى قدرة الطلاب على فهم ما يدرسه المعلمون. تقويم تعليم اللغة الأجنبية في جميع الفصول هو نفسه. يستخدم هذا التقويم بشكل أساسي اختبار مكتوب واختبار شفهي. تقويم التعليم الذي يتم إجراؤه للطلاب، بالطبع هناك تعديلات تم إجراؤها من قبلهم، مثل تعديلات الوقت والنهج الفردية.

في برنامج نشاط ادارة اللغة، يتم إجراء التقييم في غاية كل مرة وجهاً لوجه وفي هاية العام الدراسي. تتخذ التقييمات التي يتم إجراؤها في فاية كل لقاء وجهاً لوجه عدة أشكال، بما في ذلك: الاختبارات الكتابية والاختبارات الشفوية وتقييمات نتائج عمل الطلاب. 32

31 Wahyu Setyabudi, "Manajemen program pembelajaran Bahasa Arab di Pondok Pesantren Darussalam" (Tesis, Universitas Islam Negeri Maulana Malik Ibrahim, 2018), hlm. 73.

32 Shiddiq, “Model Pembelajaran Bahasa Arab di Ma'had Al-Jami'ah Walisongo Semarang," hlm. 108.

253 | Tarbiyatuna: Jurnal Pendidikan Ilmiah Vol. 5 No. 2 (Desember) 2020 
يقام نشاط التقويم في معهد الجامعة والي سانجا سمارانج في فاية الفصل الدراسي، لذلك في عام واحد يتم التقويم مرتين، أي في نصف الفصل الدراسي وفي آخره. يتم إعطاء الطلاب أسئلة اختبار تحتوي على مادة لفصل دراسي واحد للاختبارات الكتابية الشفوية، بينما يقوم المعلمون بإجراء التقويمات في الممارسة اليومية، على سبيل المثال من المحادثات والمناظرات وغيرها. نوع التقويم المستخدم في معهد الجامعة والي سانجا سمارانج هو من خلال مراقبة الاستمرارية في الحياة اليومية، والتقييم الكتابي وشفهيًا. 33 الخطوة الأخيرة من تخطيط التعليم هي كيف يعرف المعلم نتائج تعليم الطلاب من خلال تقويم التعليم. من المهم جلًا إجراء التقيم في الدرس لمعرفة مدى تقدم الطلاب أثناء عملية تعليم اللغة العربية، وكذلك لمعرفة ما إذا كان التعليم الذي تم قد حقق الأهداف المحددة مسبقًا في البداية أم لا. لذلك، يتم إجراء تقويم التعليم في الجامعة والي سانجا مرتين، في نصف الفصل الدراسي وآخره.

\section{خلاصة}

التخطيط في الأساس شيء مهم جدًا ولا يمكن فصله عن حياة الإنسان، وكذلك في مجال التخطيط التعليم يلعب دورًا مهمًا في تحقيق هدف في التعلم. ليس في المؤسسات الرسمية فقط، يجب أيضًا تطبيق التخطيط في المؤسسات غير الرسمية مثل المعهد. يُعد معهد الجامعة والي سانجا سمارانج من بين هؤلاء الذين ينفذون خطة في بجال اللغة.

في عملية إعداد تخطيط التعليم، من الضروري اتخاذ قرارات بشأن: صياغة أهداف تعليم اللغة العربية، وتحديد والمواد التعليمية، وتحديد وسائل وطرق التعليم، وتحديد التقويم للحصول على

33 Susdiasih, "Manajemen pembelajaran bahasa dalam meningkatkan kemampuan berbahasa asing (studi di Ma’had Al-Jami'ah Walisongo Semarang),” hlm. 92. 
مخرجات تعليم الطلاب. بعد إجراء بحث حول تخطيط التعليم في معهد الجامعة والي سانجا سمارانج، كانت النتائج: 1) في صياغة أهداف التعليم بمعهد الجامعة هو العملية الجيدة، لأنه تم تكييفه مع الرؤية والرسالة في المؤسسة. 2) المواد التعليمية المستخدمة في تعليم اللغة العربية المستخدمة في معهد الجامعة هي الكتاب بالموضوع " سلسلة في تعليم اللغة العربية - العربية بسيطة " وهي تصنّف من كتاب "سلسلة تعليم اللغة العربية" المصطوع التصني 3) تحديد الوسائل والطرق في تعليم اللغة العربية يتلاءم مع حالة الطلاب ومستويات الفصل. 4) يعترف بالتقويم مرتين في السنة في كل فصل دراسي.

لذلك قيل أن تخطيط لتعليم اللغة العبية في جامعة والي سانجا يعد جيدًا لأنه يبدأ بصياغة الأهداف والمواد التعليمية، ثم تعديد وسائل وطرق التعيم وينتهي با تعديد التقويم. هذه مراحل التخطيط، بدءًا من صياغة الأهداف إلى كيفية صياغة التقويم الذي سيتم إجراؤه وبحميعه قبل تعليم اللغة العربية في معهد الجامعة والي سانجا.

Abdullah, Shodiq. Evaluasi Pembelajaran konsep dasar, teori dan aplikasi. Semarang: Pustaka Rizki Putra, 2012.

Alifiyah, Ika, Ali Imron, dan Juharyanto Juharyanto. "Kepemimpinan Visioner Kepala Sekolah dalam Mengembangkan Karakter Peserta Didik." JAMP: Jurnal Administrasi dan Manajemen Pendidikan 2, no. 1 (2019): 32-39.

Aliyah, Varda Himmatul, dan Danial Hilmi. "Manajemen Perencanaan Program Bahasa Arab Di Mayantara School Malang." Arabia 11, no. 1 (2019): 17590.

Al-Khauly, Muhammad Ali. Qamus al-Tarbiyah Inggris Arab. Beirut: Dar-li ilmi alMalayin, 1981. 
Ardinal, Eva. "Manajemen Pembelajaran Bahasa Dalam Meningkatkan Kemampuan Bahasa Arab Dan Inggris (Studi Di Ma'had Al-Jami'ah IAIN Kerinci)." Tarbawi: Jurnal Ilmu Pendidikan 13, no. 1 (2017): 83-95.

Hamid, M. Abdul, Danial Hilmi, dan M. Syaiful Mustofa. "Pengembangan Bahan Ajar Bahasa Arab Berbasis Teori Belajar Konstruktivisme untuk Mahasiswa." Arabi: Journal of Arabic Studies 4, no. 1 (2019): 100-114.

Ismail. "Visi dan Misi Depag." Balai Diklat Pegawai Teknis Keagamaan Surabaya, 2005.

Jannah, Siti Raudhatul. "Karakteristik dan Spektrum Manajemen Pendidikan Islam." Al-Fikrah: Jurnal Kependidikan Islam IAIN Sulthan Thaha Saifuddin 4 (2013): 56498.

Khozin. Jejak-jejak Pendidikan Islam di Indonesia: Rekonstruksi Sejarah untuk Aksi [The footsteps of Islamic education in Indonesia: Reconstructing history for action](revised edition). Malang: UMM Press Malang, 2006.

Komariah, Aan, dan Cepi Triatna. Visionary leadership menuju sekolah efektif. Jakarta: Bumi Aksara, 2005.

Majid, Abdul. "Perencanaan pembelajaran mengembangkan kompetensi guru." Bandung: PT Remaja Rosdakarya, 2011.

Moleong, Lexy J. Metodologi penelitian kualitatif. Bandung: Remaja Rosda Karya, 2014.

Muchsin, Bashori, Moh Sulthon, dan Abdul Wahid. Pendidikan Islam humanistik: alternatif pendidikan pembebasan anak. Bandung: Refika Aditama, 2010.

Mulyono, M. A. Manajemen Administrasi dan Organisasi Pendidikan. Yogyakarta: Ar-Ruzz Media, 2008.

Munir. Perencanaan Sistem Pengajaran Bahasa Arab; Teori Dan Praktik. Jakarta: Kencana, 2016.

Nadlir, M. "Perencanaan pembelajaran berbasis karakter." Jurnal Pendidikan Agama Islam (Journal of Islamic Education Studies) 1, no. 2 (2013): 338-52.

Sabirin. "Perencanaan Kepala Sekolah Tentang Pembelajaran." Jurnal Tabularasa PPS Unimer 9, no. 1 (Juni 2012).

“Selayang Pandang |." Diakses $31 \quad$ Desember 2020. http://mahad.walisongo.ac.id/?page_id=16. 


$$
\text { تخطيط تعليم اللغة العربية في معهد الجامعة و الي سانجا سمار انج }
$$

Setyabudi, Wahyu. "Manajemen program pembelajaran Bahasa Arab di Pondok Pesantren Darussalam." Tesis, Universitas Islam Negeri Maulana Malik Ibrahim, 2018.

Shiddiq, Jamaluddin. "Model Pembelajaran Bahasa Arab di Ma'had Al-Jami'ah Walisongo Semarang." LISANIA: Journal of Arabic Education and Literature 2, no. 2 (2018): 102-20.

Susdiasih, Nur Indah Tri. "Manajemen pembelajaran bahasa dalam meningkatkan kemampuan berbahasa asing (studi di Ma'had Al-Jami'ah Walisongo Semarang)." UIN Walisongo, 2015. 